\title{
Fabrication of surrogate glasses with tektite composition
}

\author{
Ken G. Foos ${ }^{1} \cdot$ Troy Y. Ansell $^{1}$ (D ) Raymond P. Mariella Jr. ${ }^{2} \cdot$ Claudia C. Luhrs $^{1}$
}

Received: 21 February 2019 / Published online: 1 June 2019

(c) The Author(s) 2019

\begin{abstract}
Surrogate glasses were fabricated by the sol-gel process aiming to produce compositions similar to naturally occurring tektite. The volatile species in the xerogel samples were removed by heat treatments. All products were characterized by thermal analysis, scanning electron microscopy, X-ray diffraction and energy dispersive spectroscopic techniques. The elemental distribution in the surrogates was found to be more homogeneous than the one observed in natural materials. This work presents an alternative to generate target materials for the validation of techniques aimed to comminute samples in the nuclear forensics field, making the comparison between the pre and post-treatments more viable.
\end{abstract}

Keywords Sol-gel process $\cdot$ Surrogate glasses $\cdot$ Tektite $\cdot$ Characterization of synthetic glasses

\section{Introduction}

Critical to any nuclear forensics investigation are the chemical, physical, and isotopic analyses of the gathered evidence [1-3]. Man-made signatures derived from illicit nuclear devices are either detected directly as in artificial isotope detection [1] or inferred from the observation of unique isotopic and/or chemical markers [4, 5]. For a nuclear blast or similar event, debris is gathered for analysis, which often means soil and/or sediment samples collected from the vicinity of the event. Whatever the source maybe, elements of interest must be separated in a way that contaminates are not introduced in the processing of specimens. In addition, because sample sizes are often small, processing of samples should involve as little loss of material as possible [2, 6]. These two restrictions, separation of components and small amounts of material available, place limits on the typical separation techniques employed, e.g. mechanical comminution or chemical separation by dissolution with a concentrated acid. To solve these problems, a new technique for collecting specimens was developed involving the rapid

Troy Y. Ansell

troy.ansell@nps.edu

1 Mechanical and Aerospace Engineering, Naval Postgraduate School, 700 Dyer Road, Monterey, CA 93943-5114, USA

2 Lawrence Livermore National Laboratory, Mail Stop L-222, 7000 East Avenue, PO Box 808, Livermore, CA 94550, USA communications of samples termed laser-driven hydrothermal processing (LDHP) [6, 7].

Initial testing of LDHP was performed on quartzite [6] and concrete [8] by Mariella et al. Further studies conducted at the Naval Postgraduate School by Menon et al., was performed on naturally occurring minerals, tektite and obsidian $[9,10]$. The aim of the later work was to characterize LDHP processed material like trinitite, a glass which was formed during the first atomic bomb test. Both tektite and obsidian bear similar methods of formation and composition to trinitite [11]. Tektite was specifically investigated because the glass forms under high temperature and pressure for a short duration followed by rapid quenching [12, 13]. The heterogeneous microstructure of naturally occurring minerals makes difficult a direct correlation between specimen composition before and after LDHP. Thus, in order to evaluate the mechanism and processing conditions of LDHP or similar techniques, a homogeneous sample will be ideal [14]. This requires the synthesis of surrogate glasses with a similar chemical make-up to tektite but with a homogeneous elemental distribution.

Surrogate glasses have been produced to simulate radioactive materials [15-17]. The composition of fission products as a result of differences in condensation rates after a nuclear blast was also simulated by Carney et al. where surrogate glass based on the polymerization of tetraethyl orthosilicate were produced. Trace amounts of uranium was incorporated into the glass, which then was subjected to neutron irradiation. Isotopic measurements were conducted on 
the resulting fission products [15]. Synthetic melt glass was also designed to simulate trinitite. A high-temperature furnace was used to rapidly cool a mixture of metal oxides and $\mathrm{SiO}_{2}$ leading to formation of melt glass with similar chemical composition and morphology to trinitite [17]. These trinitite surrogates were processed at high temperature and exhibited a heterogeneous morphology.

This work, in contrast, aims to develop a protocol to fabricate surrogate glasses that resemble the elemental composition of tektite while exhibiting a homogeneous phase distribution. It is worth noting that the term tektite refers to natural glass formed during meteroite impacts, they are found around the world and present variation in elemental make-up. Table 1 shows examples of tektite compositions, expressed as oxides, that were used as the target in this study. Moldavite, a form of tektite, was used for inclusion distribution comparative microscopic analysis. Unlike previous surrogate development, the surrogates produced here had a more complex composition, including up to eight different cations, and a lower temperature processing technique. The method described herein to produce a glassy surrogate could enable the generation of specimens with homogeneous phase distribution, thus, all regions of the sample before forensic processing are equivalent simplifying evaluation of the material under scrutiny and validating rapid communication techniques (LDHP in this case).

\section{Experimental}

\section{Fabrication}

Samples were fabricated by the sol-gel process, a multistep wet chemical method of producing materials (usually

Table 1 Chemical composition of Indonesian tektite (Mama's Minerals, Albuquerque, NM, USA) measured by EDS [9] and compared to the average composition of tektite gathered from the Australasian strewn field [18]

\begin{tabular}{|c|c|c|}
\hline & $\begin{array}{l}\text { Measured composition } \\
\text { (wt\%) from [9] }\end{array}$ & $\begin{array}{l}\text { Average composition } \\
(\mathrm{wt} \%) \text { from [18-20] }\end{array}$ \\
\hline $\mathrm{SiO}_{2}$ & $73.04 \pm 3.65$ & $68.90 \pm 5.41$ \\
\hline $\mathrm{Al}_{2} \mathrm{O}_{3}$ & $12.34 \pm 0.62$ & $13.96 \pm 2.78$ \\
\hline $\mathrm{FeO}$ & $5.98 \pm 0.30$ & $4.98 \pm 1.14$ \\
\hline $\mathrm{K}_{2} \mathrm{O}$ & $2.54 \pm 0.13$ & $2.26 \pm 0.77$ \\
\hline $\mathrm{MgO}$ & $2.34 \pm 0.12$ & $2.66 \pm 3.91$ \\
\hline $\mathrm{CaO}$ & $2.05 \pm 0.10$ & $2.57 \pm 1.53$ \\
\hline $\mathrm{TiO}_{2}$ & $0.90 \pm 0.05$ & $0.70 \pm 0.32$ \\
\hline $\mathrm{Na}_{2} \mathrm{O}$ & $0.76 \pm 0.04$ & $1.25 \pm 1.74$ \\
\hline
\end{tabular}

Chemical composition of Australasian tektites and microtektites were determined by atomic absorption spectroscopy and emission spectroscopy [19] and electron microprobe analysis [20] respectively silica and titania based materials, e.g. solid oxide ceramic fabrication) with greater homogeneity than other methods and at lower processing temperatures [21-23]. The general steps in this method begin with hydrolysis where liquid or powder precursors are mixed with water and other solvents, usually alcohols, to form the "sol." Water and other organics are removed through condensation leading to limited polymerization [24]. Growth of polymer networks leads to linking and the formation of a "gel," a soft jelly-like solid (the gel in this case is a xerogel). Drying and dehydration, conducted at moderate temperatures, removes more of the liquid precursors trapped in pores of the gel. The final step is a high temperature processing step, densification, leading to a dense final product. In depth reviews of the process include [25-30].

Table 2 lists all the precursors and catalysts used in the fabrication of the surrogates. The chemicals are grouped according to the $\mathrm{pH}$ of the final solution, e.g. hydroxides are found exclusively in the high (basic) $\mathrm{pH}$ formulations while hydrochloric acid is found in the low (acid) $\mathrm{pH}$ formulations. Table 2 also lists the element constituents provided, e.g. aluminum was provided by aluminum nitrate nonahydrate for both acid and base formulations. During the hydrolysis step, chemical reactions are sped up by the addition of catalysts. For the acid surrogates, the catalyst is hydrochloric acid; for the base, ammonium hydroxide and ammonium fluoride. Deionized (DI) water and ethyl alcohol (EtOH) were used as mediums in both acid and base formulations.

For both the basic and acid $\mathrm{pH}$ formulations, two solutions were prepared separately. One solution was a mixture of the stoichiometric amounts of titanium (IV) isopropoxide, tetraethyl orthosilicate, and EtOH; here called solution 1 . The second solution, solution 2, was a mixture of the stoichiometric amounts to produce the composition presented in Table 1 of the chemical catalysts and the other chemical precursors in EtOH and DI water. Solution 1 was the same for both basic and acid $\mathrm{pH}$ formulations. Chemicals mixed in solution 2; however, depended on the $\mathrm{pH}$ of the formulation. Solution $2 \mathrm{~A}$ refers to the acid formulation and $2 \mathrm{~B}$ for the basic formulation.

The procedure for both formulations was the same; however, the chemical precursors and catalysts were different as stated before. For the acid $\mathrm{pH}$ formulation, solution $2 \mathrm{~A}$ contained hydrochloric acid while the basic solutions had ammonium fluoride and ammonium hydroxide. To get magnesium, potassium, and sodium into the samples via the basic formulation, representative hydroxides were added to solution 2B. For the acid formulation, hydroxides were replaced with potassium bromide, magnesium nitrate hexahydrate, and sodium nitrate.

For both acid and base, EtOH and the chemical catalyst was added to DI water. Then the chemical precursors were added to solution $2 \mathrm{~A}$ or $2 \mathrm{~B}$ one by one until completely 
Table 2 Chemical precursors, solvents and catalysts used during both acid and basic $\mathrm{pH}$ formulation of surrogates

\begin{tabular}{|c|c|c|c|c|}
\hline $\mathrm{pH}$ & Chemical name & Chemical formula & Constituent & Solution \\
\hline Acid, base & Aluminum nitrate nonahydrate & $\mathrm{Al}\left(\mathrm{NO}_{3}\right)_{3} \cdot 9 \mathrm{H}_{2} \mathrm{O}$ & Al & $2 \mathrm{~A}, 2 \mathrm{~B}$ \\
\hline Acid, base & Calcium chloride & $\mathrm{CaCl}_{2}$ & $\mathrm{Ca}$ & $2 \mathrm{~A}, 2 \mathrm{~B}$ \\
\hline Acid, base & Deionized (DI) water & $\mathrm{H}_{2} \mathrm{O}$ & (Medium) & $2 \mathrm{~A}, 2 \mathrm{~B}$ \\
\hline Acid, base & Ethyl alcohol & $\mathrm{C}_{2} \mathrm{H}_{6} \mathrm{O}$ & (Medium) & $1,2 \mathrm{~A}, 2 \mathrm{~B}$ \\
\hline Acid, base & Iron (III) nitrate nonahydrate & $\mathrm{Fe}\left(\mathrm{NO}_{3}\right)_{3} \cdot 9 \mathrm{H}_{2} \mathrm{O}$ & $\mathrm{Fe}$ & $2 \mathrm{~A}, 2 \mathrm{~B}$ \\
\hline Acid, base & Tetraethyl orthosilicate & $\mathrm{C}_{8} \mathrm{H}_{20} \mathrm{O}_{4} \mathrm{Si}$ & $\mathrm{Si}$ & 1 \\
\hline Acid, base & Titanium (IV) isopropoxide & $\mathrm{C}_{12} \mathrm{H}_{28} \mathrm{O}_{4} \mathrm{Ti}$ & $\mathrm{Ti}$ & 1 \\
\hline Acid & Hydrochloric acid (2.0 M) & $\mathrm{HCl}$ & (Catalyst) & $2 \mathrm{~A}$ \\
\hline Acid & Magnesium nitrate hexahydrate & $\mathrm{Mg}\left(\mathrm{NO}_{3}\right)_{2} \cdot 6 \mathrm{H}_{2} \mathrm{O}$ & $\mathrm{Mg}$ & $2 \mathrm{~A}$ \\
\hline Acid & Potassium bromide & $\mathrm{KBr}$ & $\mathrm{K}$ & $2 \mathrm{~A}$ \\
\hline Acid & Sodium nitrate & $\mathrm{Na}\left(\mathrm{NO}_{3}\right)$ & $\mathrm{Na}$ & $2 \mathrm{~A}$ \\
\hline Base & Ammonium fluoride (0.5 M) & $\mathrm{NH}_{4} \mathrm{~F}$ & (Catalyst) & $2 \mathrm{~B}$ \\
\hline Base & Ammonium hydroxide (14.8 M) & $\mathrm{NH}_{4} \mathrm{OH}$ & (Catalyst) & $2 \mathrm{~B}$ \\
\hline Base & Magnesium hydroxide & $\mathrm{Mg}(\mathrm{OH})_{2}$ & $\mathrm{Mg}$ & 2B \\
\hline Base & Potassium hydroxide & $\mathrm{KOH}$ & $\mathrm{K}$ & $2 \mathrm{~B}$ \\
\hline Base & Sodium hydroxide & $\mathrm{NaOH}$ & $\mathrm{Na}$ & $2 \mathrm{~B}$ \\
\hline
\end{tabular}

dissolved and/or a homogeneous mixture was reached. The final mixing step, both for $2 \mathrm{~A}$ and $2 \mathrm{~B}$ solutions, was to add finely crushed iron (III) nitrate nonahydrate and mix until completely dissolved.

Solution 1 was placed in a sand bath which was set on top of a hot plate with a magnetic dial. The magnetic field was turned on and a magnetic stirrer was placed in solution 1 to provide continuous mixing while the hot plate was set to $80.0^{\circ} \mathrm{C}$. Solution $2 \mathrm{~A}$ or $2 \mathrm{~B}$ was then slowly added to solution 1 . The magnetic stirrer was left in the combined solution until the formation of the gel prevented further movement.

Following the formation of a gel, the samples were placed in a Barnstead Lab-Line L-C oven and covered with a concave glass cover to allow enough off-gassing. The oven was set to $60{ }^{\circ} \mathrm{C}$ and the samples were dried for 60,80 or $120 \mathrm{~min}$. The oven was then turned off and the samples were kept in the oven to finish drying. After characterization of the as-fabricated glass surrogates, further heat treatment was performed on samples for the dehydration step.

Dried samples (xerogel) were placed in a high alumina combustion boat (CoorsTek), which was then placed in a programmable furnace, a Lindberg Blue M (Thermo Scientific). The samples were exposed to air, which flowed past the samples during heating. This allowed vapors from further off-gassing to flow away from the samples. Two different heat treatments were applied.

In heat treatment \#1 (HT1), the oven was heated to $50{ }^{\circ} \mathrm{C}$ over a period of $250 \mathrm{~min}$ and allowed to dwell for $120 \mathrm{~min}$. The oven then was set to $110^{\circ} \mathrm{C}$ and reached this temperature after $600 \mathrm{~min}$ and allowed to dwell for $120 \mathrm{~min}$. The final temperature was set to $350{ }^{\circ} \mathrm{C}$ and heated for $1200 \mathrm{~min}$, after which, the oven dwelled for $120 \mathrm{~min}$. In heat treatment \#2 (HT2), the oven was set to $825^{\circ} \mathrm{C}$ and heated up to this temperature over a period of $800 \mathrm{~min}$ and then allowed to dwell here for $120 \mathrm{~min}$. For surrogates produced via the basic or acid formulation, some samples were given HT1 while others were given HT2. The resulting properties were then characterized and compared. Heat treated samples were also compared to the as-fabricated xerogels. From this point on samples not heat treated will be referred as acid or basic xerogel and heat-treated samples will be called acid or basic surrogates.

\section{Characterization techniques}

Thermal analysis was conducted utilizing a Netzsch STA 449 F3 Jupiter with simultaneous thermogravimetric analysis (TGA) and differential scanning calorimetry (DSC). Samples were analyzed either as solid sections or mechanically pulverized in a mortar and pestle. The specimens were placed in alumina crucibles, loaded into the TGA/DSC, and exposed to an $\mathrm{Ar} / \mathrm{O}_{2}$ atmosphere at temperatures up to $1200{ }^{\circ} \mathrm{C}$ and a heating rate of $2.0^{\circ} \mathrm{C} / \mathrm{min}$. This technique allowed determining the temperatures at which most volatiles species were lost and the points where amorphous to crystalline transformations occurred.

$\mathrm{X}$-ray diffraction (XRD) analysis was conducted on the powder specimens using a Rigaku MiniFlex $600 \mathrm{X}$-ray diffractometer operated at $40 \mathrm{kV}$ and $15 \mathrm{~mA}$ with a $\mathrm{Cu}$ metal target (1.5418 $\mathrm{K} \alpha$ lines). Diffraction data was collected in the $2 \theta$ range of $10^{\circ}-90^{\circ}$ at $3^{\circ}-5^{\circ} / \mathrm{min}$ with a step width of $0.02^{\circ}$. Collected data was then analyzed using Rigaku PDXL software and XRD processing, identification, and quantification software, JADE, version 9. The crystallinity was calculated using PDXL, an integrated powder X-ray analysis software package that provides various analysis functions 
based on the experimental powder X-ray diffraction pattern. Sample data was loaded in PDXL; peak and background fitting was performed; peaks were then identified including amorphous peaks; and finally whole powder pattern fitting was performed. The percent crystallinity was then automatically calculated by PDXL.

For scanning electron microscopy (SEM), a 3.0-8.0$\mathrm{nm}$ layer of $80 \mathrm{Pt}-20 \mathrm{Pd}$ coating was deposited on bulk and crushed samples to reduce surface charging. The thin layers were applied by sputter deposition using a Cressington Sputter Coater 208HR. Microstructural imaging was performed using a Zeiss Neon 40 field emission SEM. Connected to the SEM was an EDAX EDS system with a solid-state detector. The EDS spectra and mappings were generating using a beam of electrons accelerated at $20 \mathrm{kV}$. Elements present were quantified as elements, with the difference made up by oxygen, and corrected using a ZAF correction [31], i.e. difference by oxygen standardless (semi-quantitative) method. With these techniques the microstructural features and phase distributions were studied. For back-scatter electron imaging, a LEO four-quadrant back-scatter detector, type 815 , was used.

\section{Results and discussion}

\section{Thermal analysis}

The mass and heat flow changes suffered by the samples when heated for both acid and basic surrogate glasses are shown in Figs. 1 and 2, respectively. The thermal behavior of surrogate glasses fabricated by the two approaches was similar. In Fig. 1, the acid xerogel presents two large endothermic peaks in the DSC data: one event below $100^{\circ} \mathrm{C}$ and the other event occurring between 100 and $200{ }^{\circ} \mathrm{C}$. These signals are due to the off-gassing of solvents (ethanol, water) and other volatile components respectively. The second peak seems to have more than one maxima, such effect might be due to the simultaneous dehydration and decomposition of multiple compounds. The DSC signal then presents a smaller peak that corresponds to an extended event, likely linked to the loss of organic components that occurs between 200 and $400{ }^{\circ} \mathrm{C}$. The TGA mass losses align with the transitions previously mentioned; approximately $30 \%$ of the mass is lost in the off-gassing that occurs below $100{ }^{\circ} \mathrm{C}$, closely followed by another $30 \%$ loss up to $200{ }^{\circ} \mathrm{C}$, then the behavior changes, the mass gets reduced at a slower rate, reaching a steady weight at $400{ }^{\circ} \mathrm{C}$ with a residual mass of $32 \%$ of the original. The heat flow signal suffers a transition at $800{ }^{\circ} \mathrm{C}$ that does not involve mass changes in the TGA; such is linked to crystallization of the specimen as X-ray data will later show.

For the basic formulation, the xerogel decomposes in a similar fashion to the acid one, presenting DSC signal and mass losses below $100{ }^{\circ} \mathrm{C}$, followed by DSC peaks that encompass multiple reactions, all resulting in a mass loss of almost $60 \%$ when the temperature reaches $200{ }^{\circ} \mathrm{C}$. The sample then decomposes at a slower rate, reaching a steady mass at $400{ }^{\circ} \mathrm{C}$ with a residual mass of $31 \%$ of the original weight. The process observed in the acid sample at $800{ }^{\circ} \mathrm{C}$ is barely noticeable in the basic xerogel, looking more like an inflection in the curve than a peak. Based on the TGA/
Fig. 1 Thermogravimetric (mass\%) and differential scanning calorimetry (heat flow) data generated from heating the as-fabricated acid xerogel

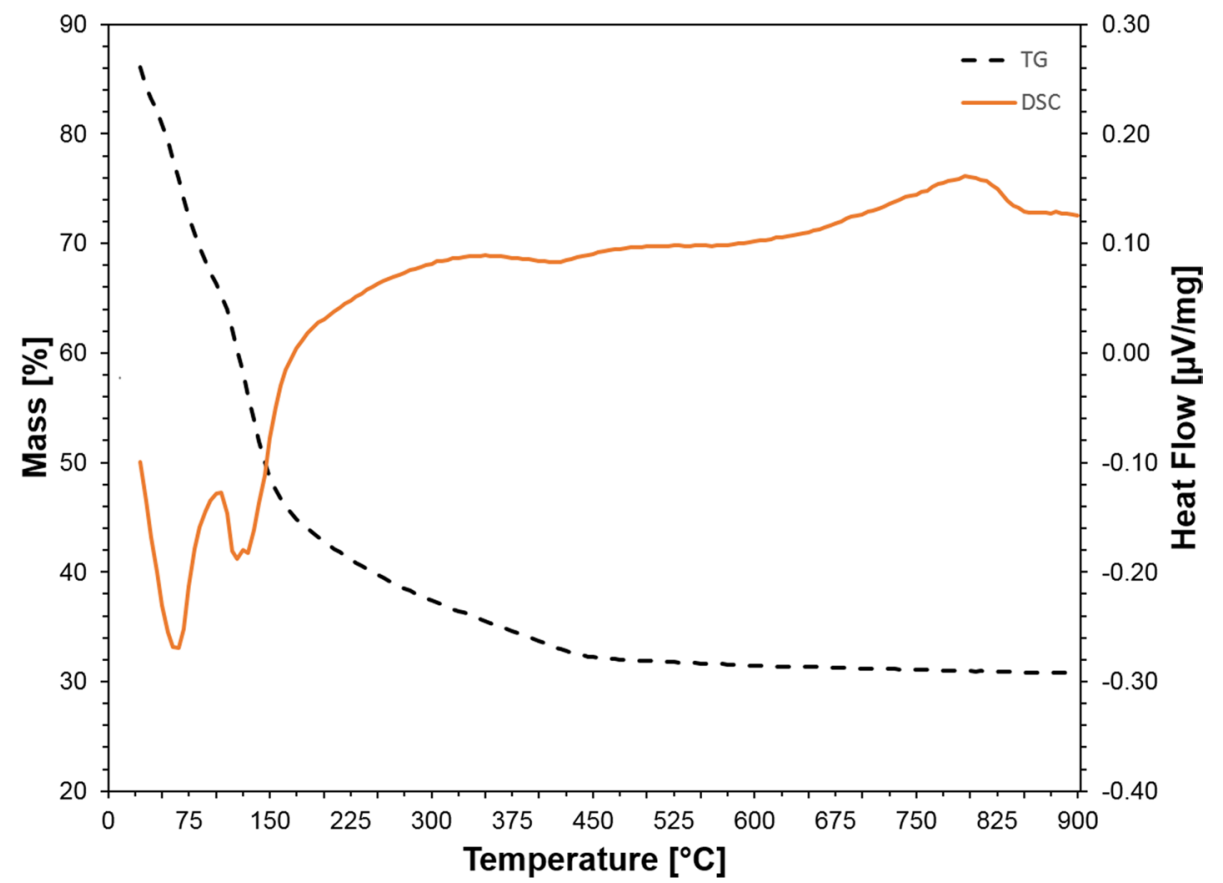


Fig. 2 Thermogravimetric (mass\%) and differential scanning calorimetry (heat flow) thermograms generated from heating the as-fabricated basic xerogel

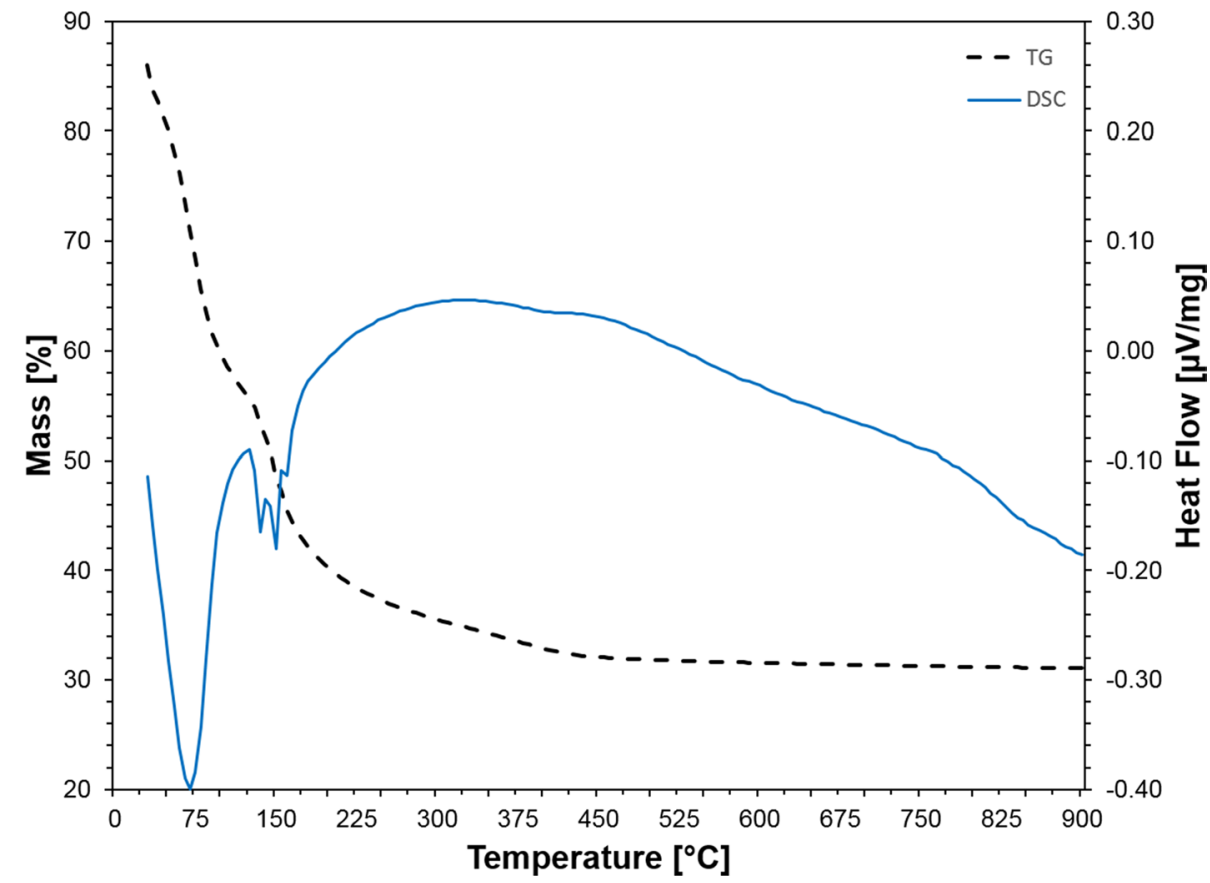

DSC data presented, it was decided that to follow the evolution of the samples, specimens will be analyzed in the (1) as-fabricated state, (2) after a $350{ }^{\circ} \mathrm{C}$ (HT1) and (3) after $825^{\circ} \mathrm{C}$ (HT2).

\section{X-ray diffraction}

Plots of X-ray diffraction of both the acid and basic surrogate materials are shown in Fig. 3a, b respectively. In Fig. 3a, the as-fabricated specimen shows a broad amorphous peak characteristic of glass phase materials. The broad peak centered around $2 \theta=26^{\circ}$ corresponds to the local scale arrangement

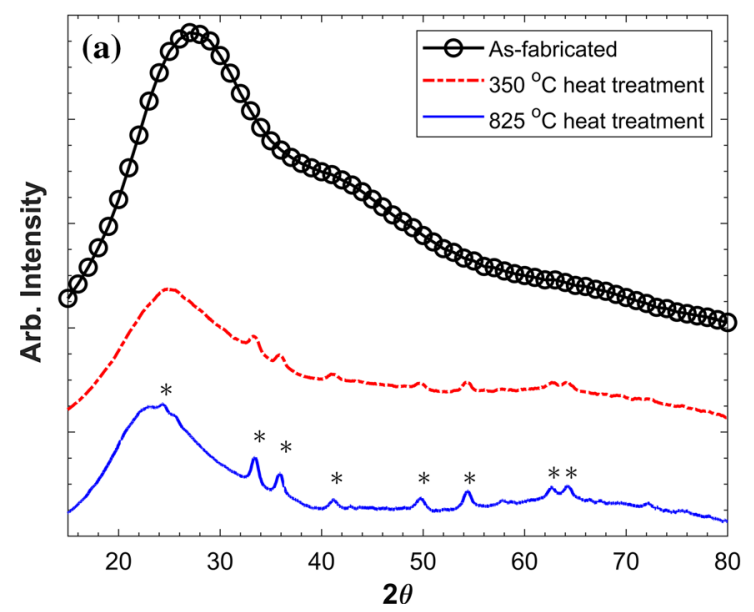

Fig. 3 X-ray diffraction patterns of a acid specimens and $\mathbf{b}$ basic specimens. Intensity was plotted with arbitrary units and $2 \theta$ values range from $15^{\circ}$ to $80^{\circ}$. The asterisk indicates major crystalline peaks. of silicon and oxygen groups [32]. There is a short plateau following the broad peak which indicates a reordering of the local structure of the glass network.

Heat treatment of samples caused a change in the arrangement of $\mathrm{Si}-\mathrm{O}$ bonds as indicated by small shifts in the position of the broad amorphous peak. Samples of this formulation partially crystallized after heat treatment at $350{ }^{\circ} \mathrm{C}$ (HT1) as indicated by the peaks overlaying the amorphous background. The intensity of the crystalline peaks increased when samples were heat treated to $825{ }^{\circ} \mathrm{C}$ (HT2). The percent crystallinity of both the acid and basic fabrications increased when the heat treatment temperature increased

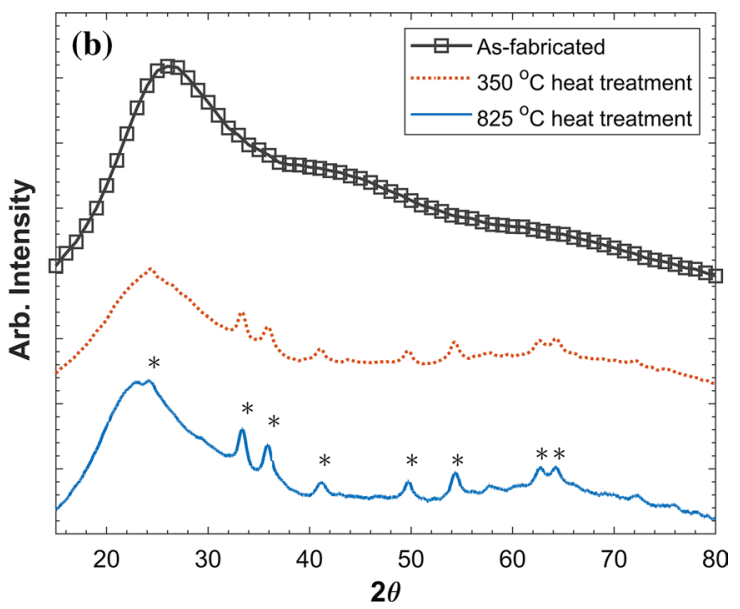

The peaks identified are believed to belong to phases in $\mathrm{CaAl}_{4} \mathrm{Fe}_{8} \mathrm{O}_{19}$ (calcium aluminum iron oxide), $\mathrm{Fe}_{9} \mathrm{TiO}_{15}$ (iron titanium oxide), and $\mathrm{Fe}_{2} \mathrm{O}_{3}$ (iron oxide) 
from $350{ }^{\circ} \mathrm{C}$ (HT1) to $825^{\circ} \mathrm{C}$ (HT2). Observed differences, in crystallinity, between acid and basic surrogates treated at $350{ }^{\circ} \mathrm{C}$ or $825^{\circ} \mathrm{C}$ due to different processing conditions.

The crystalline peaks were identified as calcium aluminum iron oxide $\left(\mathrm{CaAl}_{4} \mathrm{Fe}_{8} \mathrm{O}_{19}\right)$ PDF 00-049-1586 (ICDD, 2016), iron titanium oxide $\left(\mathrm{Fe}_{9} \mathrm{TiO}_{15}\right)$ PDF 00-054-1267 (ICDD, 2016), and/or iron (III) oxide $\left(\mathrm{Fe}_{2} \mathrm{O}_{3}\right)$ PDF 00-0011053 (ICDD, 2016) [33]. Calcium aluminum iron oxide is a part of a class of magnetoplumbites, which can be fabricated using the traditional ceramic method [34]. Crystallites of $\mathrm{Fe}_{9} \mathrm{TiO}_{15}$ have been previously formed via the sol-gel method [35]. Silica aerogels and xerogels produced with iron (III) nitrate nonahydrate were shown to exhibit an allotrope of iron (III) oxide, hematite (also referred to as $\alpha-\mathrm{Fe}_{2} \mathrm{O}_{3}$ ) [36] and maghemite (also known as $\gamma-\mathrm{Fe}_{2} \mathrm{O}_{3}$ ) [36, 37], respectively. Maghemite; however, was not identified in the XRD peaks measured for both acid or basic xerogels. Therefore, the phases identified in the XRD analysis were limited to $\mathrm{Fe}_{9} \mathrm{TiO}_{15}, \alpha-\mathrm{Fe}_{2} \mathrm{O}_{3}$, or both.

$\mathrm{X}$-ray diffraction of naturally occurring tektite, as presented by Menon et al. [9], shows regions with an amorphous phase and regions with high crystallinity; in contrast, every part of the specimens analyzed herein showed the same pattern, thus inhomogeneity in XRD was not observed in as-fabricated surrogates. Calcium carbonate $\left(\mathrm{CaCO}_{3}\right)$, aluminum silicate $\left(\mathrm{Al}_{2} \mathrm{O}_{3}-\mathrm{SiO}_{2}\right)$, and sodium aluminum silicate $\left(\mathrm{Na}_{1.15} \mathrm{Al}_{1.15} \mathrm{Si}_{0.85} \mathrm{O}_{4}\right)$ were identified as the dominant crystalline components in tektite. In contrast, the synthetic samples do not show any evidence of silica or alumina crystalline components, indicating that those elements are only found as amorphous components in the surrogates produced.

\section{Microscopy and microanalysis}

Images of surrogates were captured using both a consumer grade camera and SEM as shown in Fig. 4. Upon drying, the acid xerogels were observed to be glassy yet opaque solids with an orange tinge (Fig. $4 \mathrm{a}$ ) while the basic xerogels exhibited translucence with a darker reddish hue (Fig. 4c). The color in both cases was caused by addition of the $\mathrm{Fe}$ and Ti precursors to the initial solutions. When xerogels were produced with only $\mathrm{Si}, \mathrm{Al}, \mathrm{K}$ and $\mathrm{Mg}$, dried gels were opaque and white or transparent. The difference in translucence between the two sets of xerogels in the figure was due to processing differences, i.e. different precursor chemicals leading to different gelation times (13 min for acid fabrications and nearly $60 \mathrm{~min}$ for basic fabrications) and the consequences of such differences in the bonding and structures of the newly formed solids.

As-fabricated xerogels initially formed fragile centimeter sized solids. Shown in Fig. 4a, c, pieces of as-fabricated xerogels broke away from initial pieces with little effort. During SEM sample preparation, extensive cracking of xerogels was observed as seen in SEM images (Fig. 4b, d). Heat treatment caused further breakage of xerogels to sub-millimeter sized pieces. This was due to off-gassing of solvents and
Fig. 4 Images and SEM images of as-fabricated surrogate glasses. Shown in $\mathbf{a}, \mathbf{b}$ are images and SEM images of an acid xerogel while $\mathbf{c}, \mathbf{d}$ are the images and SEM of as-fabricated basic xerogel
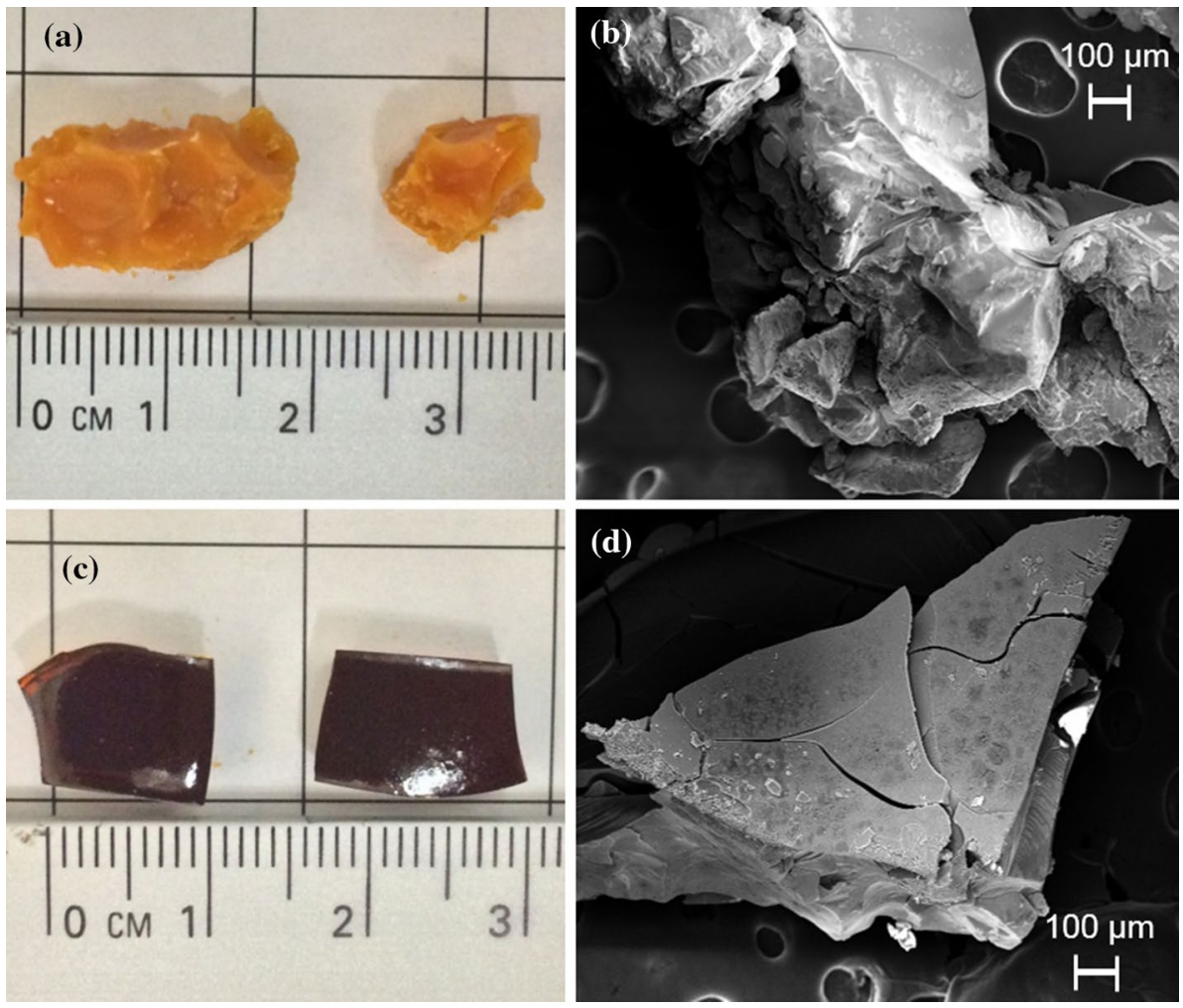
other volatiles during heating as seen in the DSC/TGA plots (Figs. 1, 2). For the acid xerogel, heat treatment caused samples to break extensively resulting in sub-millimeter sized glass shards with a translucent appearance much like the basic xerogels. No change in the visual appearance of the basic surrogates was observed except for the breaking of initially large $(>1.0 \mathrm{~cm})$ samples into smaller pieces.

For xerogels, the silica network forms the skeleton of the glass phase and porosity forms a "second" phase [38]. The rapid gel time of the acid surrogates mean a higher percentage of alcohol and water trapped during gelation leading to increased scattering of light and higher opacity. Slower gelation time in the basic surrogates leads to increased off-gassing and lower porosity ultimately leading to increased transparency. Heat-treatments removed trapped alcohol, water, and other gases allowing pores to collapse and increasing transparency in the acid surrogates $\mathrm{X}$-ray microanalysis via EDS showed a greater elemental uniformity in surrogate samples when compared to the natural specimens.

Measured and averaged results of EDS analysis on acid and basic surrogates were compared to the average tektite composition taken from Table 1. The target composition of tektite represents the average of multiple values found in the literature. For the analysis of surrogates, it is worth noting that sampling was made in multiple spots of every specimen. In all surrogate products, all the elements of interest exhibited similar composition at every spot, pointing to a uniform phase distribution. Chlorine was observed in the as-fabricated samples; however, chlorine is not a constituent of tektite [18-20]. Chlorine remains after the formation of a xerogel due to incomplete off-gassing; however, after heat treatment at $825^{\circ} \mathrm{C}(\mathrm{HT} 2)$, the surrogate products are almost completely free of it as seen in Fig. 5. When compared to as-fabricated specimens, heat treatment caused the relative iron content in the acid and basic surrogates to increase. Aluminum, calcium, and magnesium also increased in relative composition, while silicon, potassium, and sodium decreased in relative composition after heat treatment of both acid and basic surrogates. This does not mean surrogate samples lost elements like silicon or gained elements such as iron during heat treatment. The results shown in Fig. 5 signify a relative change in composition occurred due to the loss of chlorine. Heat-treated surrogates exhibited similar chemical composition despite the use of different chemical precursors in the two fabrication routes. The composition of iron in the surrogates was considerably higher than that found in tektite. Figure 5 shows the composition of surrogates are similar to tektite; however, the overall surrogate compositions were not close to the measured tektite composition found in Table 1. Adjustment of input chemicals is required to obtain the exact target composition.

Optical microscopy images of samples of moldavite show micro-meter sized inclusions as seen in Fig. 6a. Secondary electron image, in Fig. 6b, of the same moldavite sample reveal a distribution of shapes and sizes of the inclusions distributed throughout the sample. The inhomogeneity of moldavite is clear upon visual and low magnification investigation, compositional contrast was also observed as previously reported [39]. Seen in Fig. 6c, back-scatter electron imaging reveals different chemical make-up between inclusions
Fig. 5 Results of chemical analysis conducted on heattreated (HT2) acid (red) and basic (blue) surrogates and compared to the average tektite composition (green). (Color figure online)

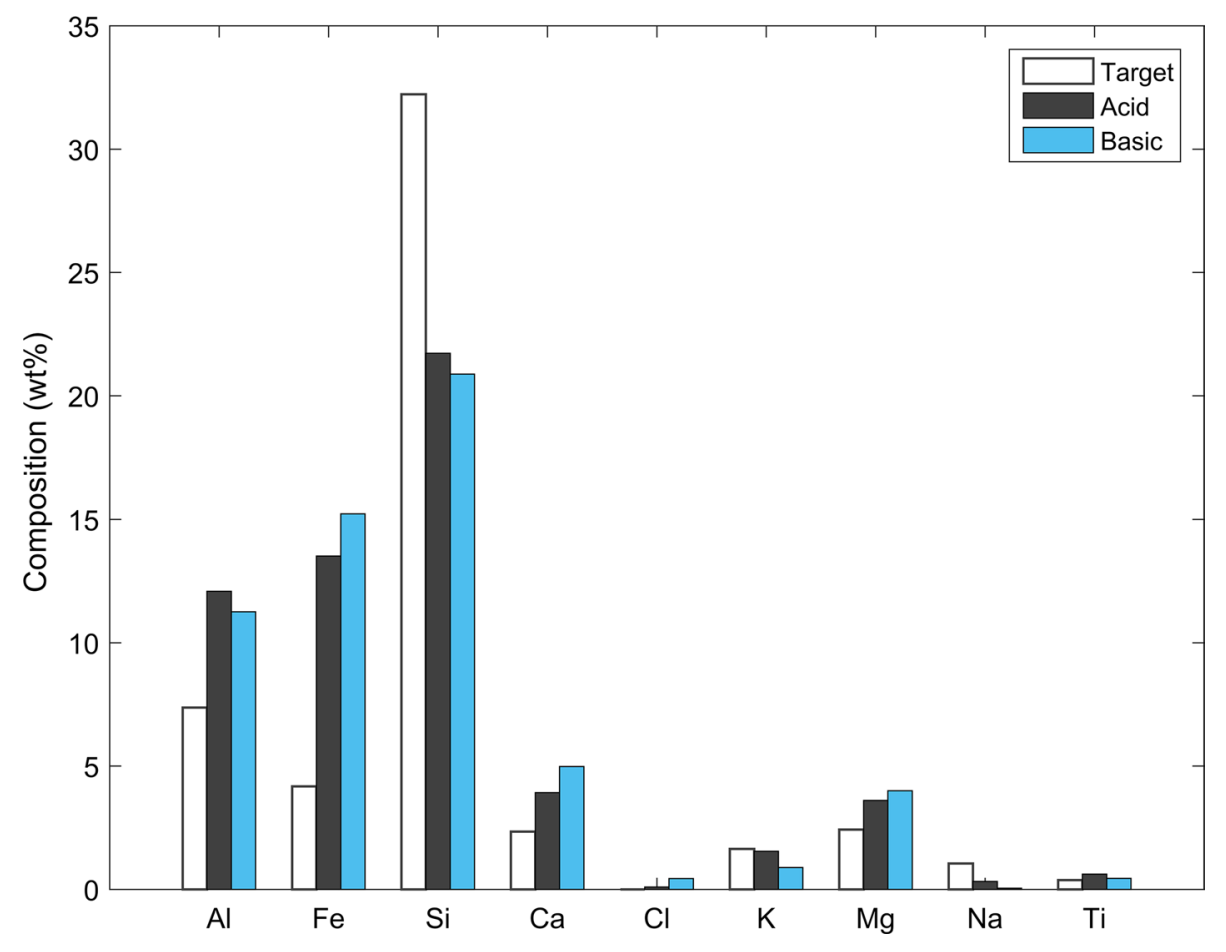



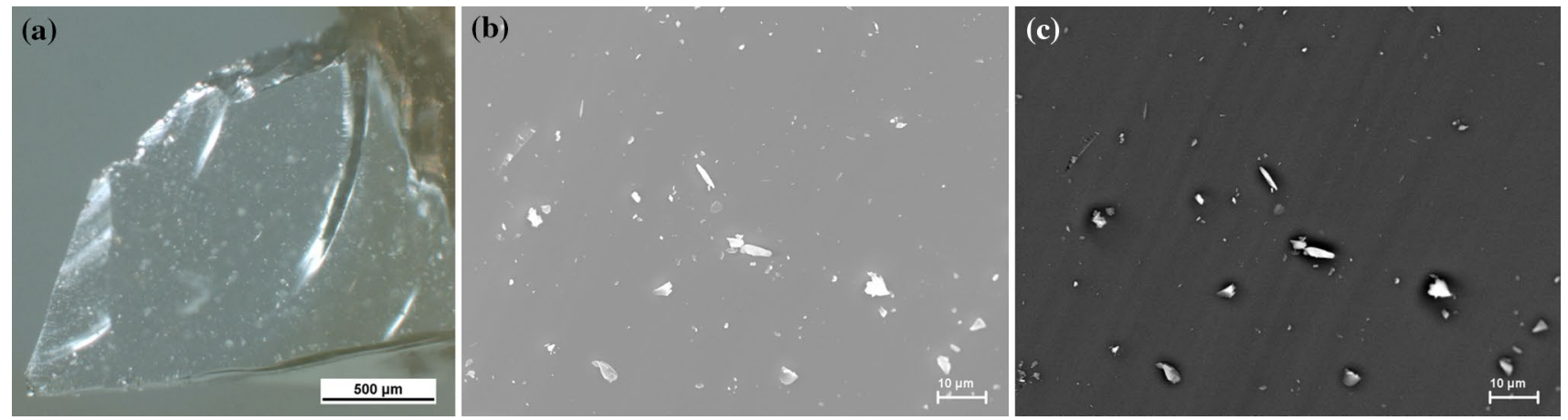

Fig. 6 Sample of moldavite seen under an a optical microscope and an electron microscope in secondary electron mode (b) and back-scatter electron mode in $\mathbf{c}$

and the surrounding silica matrix. The moldavite inclusions appear with varying contrast due to the composition and depth of the inclusion within the silica matrix. Chemical analysis showed inclusions were richer in elements such as $\mathrm{Fe}$ and/or Ti. Inclusions were also observed in as-fabricated surrogates (acid surrogate in Fig. 7a and basic surrogate in Fig. 7b); however, the size of the inclusions were quite small (submicron sizes) when compared to the moldavite inclusions and were uniformly distributed across samples studied under the electron microscope. Moreover, their distribution seems to be highly homogeneous. SEM/EDS analysis performed in multiple spots of the surrogate samples confirm the distribution and size of inclusions to be much more homogeneous than in the natural counterpart.

Figure 8 shows a secondary electron image of a heattreated (HT2) acid surrogate and EDS maps of the sample for the elements: $\mathrm{Si}, \mathrm{Fe}$, and Ti. The elements are uniformly distributed throughout the sample. Figure 8 shows that even after heat-treatment, which causes the formation of crystallites (Fig. 3), surrogate samples contain small inclusions as compared to tektite with relatively large sub-millimeter sized inclusions. Previous work on tektites found some of the observed inclusions were rich in $\mathrm{Fe}$ and $\mathrm{Ti}$ [9], the same was found in this work. At higher magnifications of heat-treated surrogate samples, EDS analysis revealed Fe-rich inclusions. Unlike in tektite; however, these inclusions were sub-micron in size. Microscopy and X-ray microanalysis found surrogate samples had similar chemical composition to tektite on average with a uniform phase distribution unlike tektite specimens. Tektite, in general, contains large inclusions rich in metals heavier than $\mathrm{Si}$, such as $\mathrm{Fe}$ and $\mathrm{Ti}$. As mentioned in the introduction, it is difficult to validate techniques with specimens in which different spots of the specimen being treated contain different composition since it would be difficult to compare, and contrast analysis performed in treated versus untreated areas. Because the elements and inclusions in the surrogates are distributed uniformly and the size of the inclusions are quite small when compared to inclusions found in tektite, it is expected that comparing spots in the untreated matrix before and after treatments will be directly comparable.

\section{Conclusions}

Surrogate glasses were fabricated to chemically resemble naturally occurring tektite but with a homogeneous distribution of elements. Heat-treatment of surrogates caused the
Fig. 7 Secondary electron images of $\mathbf{a}$ acid xerogel and $\mathbf{b}$ basic xerogel
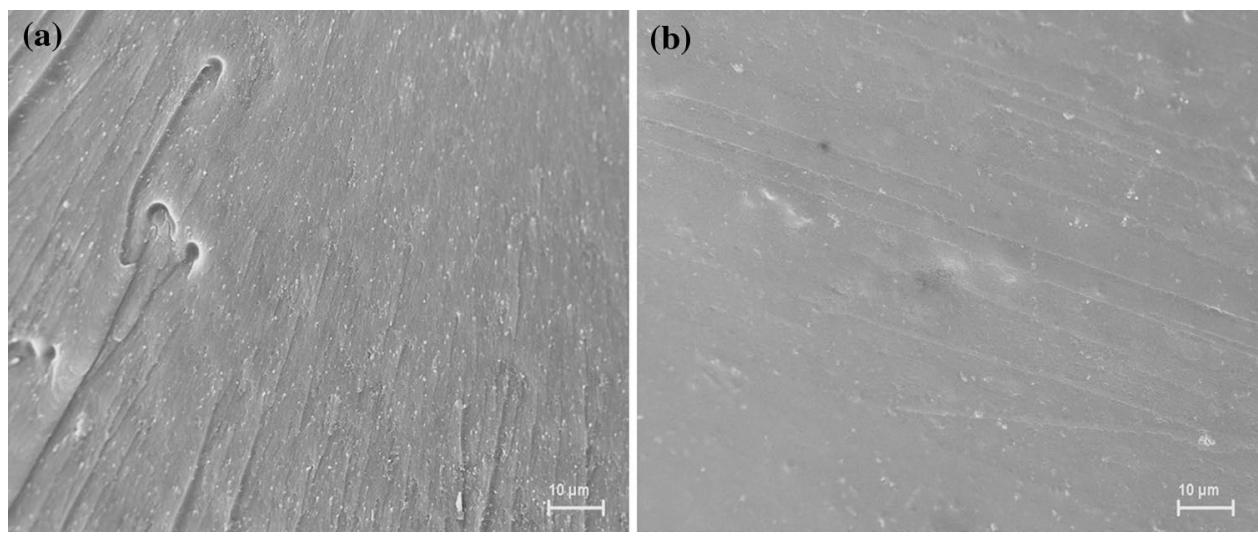
Fig. 8 Secondary electron image of a heat-treated acid surrogate and corresponding EDS maps of the elements Si, $\mathrm{Fe}$, and Ti. For interpretation of the references to color in this figure, the reader is referred to the online version of this article. (Color figure online)
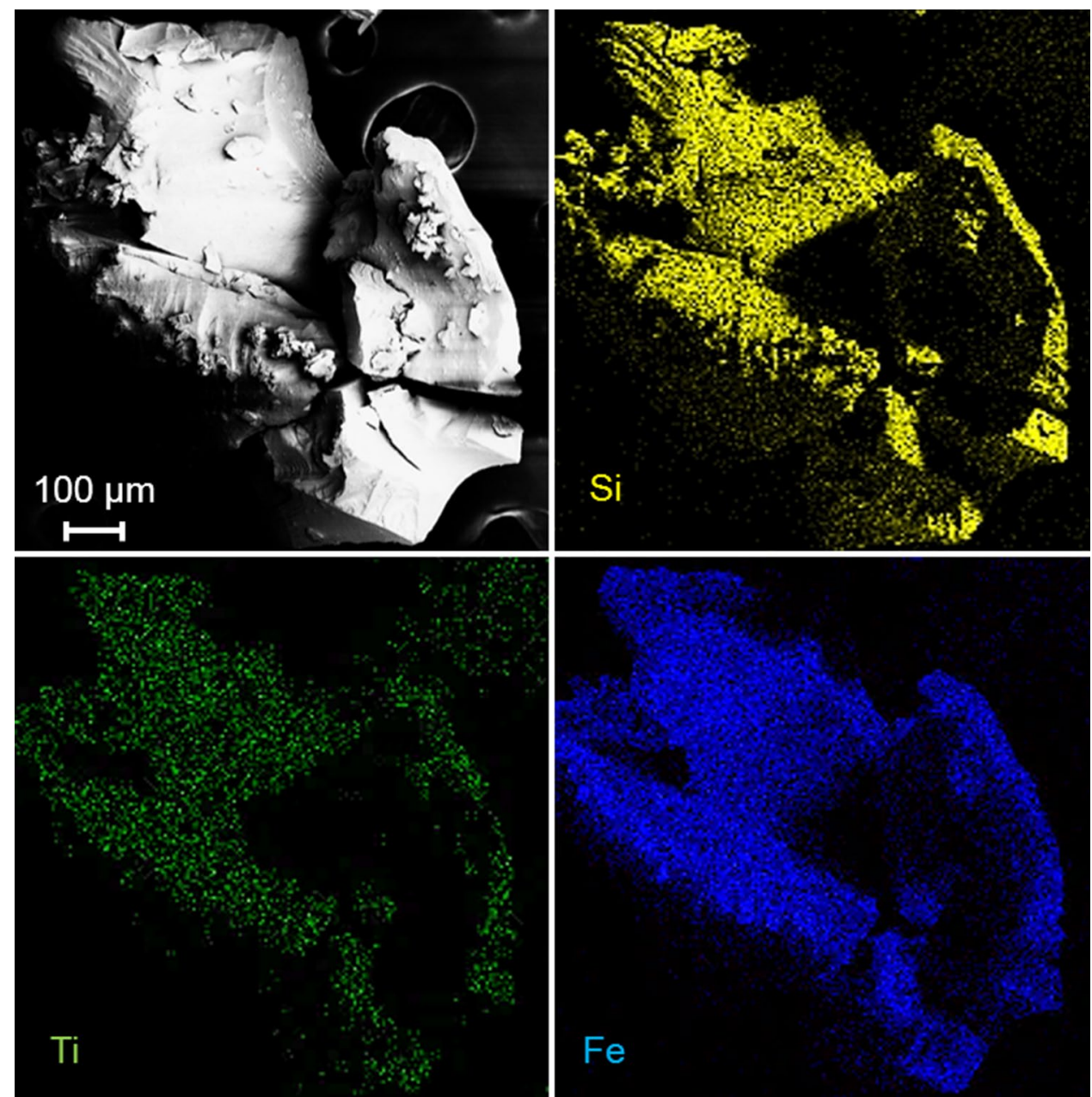

formation of Fe and Ti-rich inclusions. Simultaneous thermal analysis showed the evaporation of volatile elements such as chlorine. Thermal analysis and XRD also revealed crystallite formation during heat treatments. X-ray diffraction analysis showed as-fabricated surrogates with an amorphous phase while heat treated samples with up to $51 \mathrm{wt} \%$ and $83 \mathrm{wt} \%$ crystallinity in the acid and basic surrogates respectively. In addition, XRD indicated crystallites Fe and Ti rich, similar than inclusions found in tektite. Microscopic and chemical analysis showed surrogates had a homogeneous elemental make-up before and after heat treatment for the two routes employed (acid vs basic) while exhibiting similar chemical composition to tektite. In sum, this work presents a fabrication alternative to generate target materials for the validation of diverse techniques in the nuclear forensics field. The samples present an elemental distribution homogeneous at the micron size, what we believe is adequate to produce suitable comparisons between the pre and post-treatments.

Acknowledgements The authors appreciate the support received from DTRA through Contract HDTRA1724485 and the help that summer high school intern, Ariana Rodd, provided to this project. The authors also acknowledge the helpful discussions with Dr. Sarath Menon.

Open Access This article is distributed under the terms of the Creative Commons Attribution 4.0 International License (http://creativeco mmons.org/licenses/by/4.0/), which permits unrestricted use, distribution, and reproduction in any medium, provided you give appropriate credit to the original author(s) and the source, provide a link to the Creative Commons license, and indicate if changes were made.

\section{References}

1. Sharp N, McDonough WF, Ticknor BW et al (2014) Rapid analysis of trinitite with nuclear forensic applications for post-detonation material analyses. J Radioanal Nucl Chem 302:57-67

2. Moody KJ, Hutcheon ID, Grant PM (2005) Nuclear forensic analysis. CRC Press, Boca Raton

3. Bonamici CE, Kinman WS, Fournelle JH et al (2017) A geochemical approach to constraining the formation of glassy fallout debris from nuclear tests. Contrib Mineral Petrol 172:69-86. https ://doi.org/10.1007/s00410-016-1320-2

4. Grant PM, Moody KJ, Hutcheon ID et al (1998) Nuclear forensics in law enforcement applications. J Radioanal Nucl Chem 235:129-132 
5. Moody KJ, Grant PM (1999) Nuclear forensic analysis of thorium. J Radioanal Nucl Chem 241:157-167

6. Mariella RP Jr, Rubenchik AM, Norton MA, Donohue G (2013) Laser comminution of submerged samples. J Appl Phys 114:014904. https://doi.org/10.1063/1.4808333

7. Mariella Jr. RP, Rubenchik AM, Norton MA (2015) Laser-driven hydrothermal processing. US 2015/0321287 A1

8. Mariella RP Jr, Rubenchik AM, Fong E et al (2017) Laser-driven hydrothermal process studied with excimer laser pulses. J Appl Phys 122:075104

9. Menon S, Camargo A, Wu C-H et al (2017) Characterization of particles created by laser-driven hydrothermal processing. Mater Char 133:1-9. https://doi.org/10.1016/j.materchar.2017.09.018

10. Camargo A (2016) Characterization of particles created by laserdriven hydrothermal processing. Naval Postgraduate School, Monterey

11. Eby GN, Charnley N, Pirrie D et al (2015) Trinitite redux: mineralogy and petrology. Am Mineral 100:427-441

12. Bunch TE, Hermes RE, Moore AMT et al (2012) Very hightemperature impact melt products as evidence for cosmic airbursts and impacts 12,900 years ago. Proc Natl Acad Sci USA 109:E1903-E1912

13. Eby GN, Hermes RE, Charnley N, Smoliga JA (2010) Trinititethe atomic rock. Geol Today 26:180-185

14. Foos KG (2017) Fabrication and characterization of surrogate glasses aimed to validate nuclear forensic techniques. Naval Postgraduate School, Monterey

15. Carney KP, Finck MR, McGrath CA et al (2014) The development of radioactive glass surrogates for fallout debris. J Radioanal Nucl Chem 299:363-372. https://doi.org/10.1007/s10967-013-2800-8

16. Carney KP, Finck MR, McGrath CA et al (2013) The development of radioactive sample surrogates for training and exercises. J Radioanal Nucl Chem 296:769-773

17. Molgaard JJ, Auxier JD II, Giminaro AV et al (2015) Development of synthetic nuclear melt glass for forensic analysis. J Radioanal Nucl Chem 304:1293-1301. https://doi.org/10.1007/s1096 7-015-3941-8

18. Chapman DR (1971) Australasian tektite geographic pattern, crater and ray of origin, and theory of tektite events. J Geophys Res 76:6309-6338

19. Chapman DR, Scheiber LC (1969) Chemical investigation of Australasian tektites. J Geophys Res 74:6737-6776

20. Cassidy WA, Glass B, Heezen BC (1969) Physical and chemical properties of australasian microtektites. J Geophys Res 74:1008-1025

21. Bhatia RB, Brinker CJ, Gupta AK, Singh AK (2000) Aqueous solgel process for protein encapsulation. Chem Mater 12:2434-2441

22. Brinker CJ, Scherer GW (1989) Sol-gel science: the physics and chemistry of sol-gel processing. Academic Press, London

23. Ulrich D (1988) Prospects of sol-gel processes. J Non-Cryst Solids 100:174-193. https://doi.org/10.1016/0022-3093(88)90015-4
24. Guglielmi M, Carturan G (1988) Precursors for sol-gel preparations. J Non-Cryst Solids 100:16-30. https://doi. org/10.1016/0022-3093(88)90004-X

25. Hench LL, West JK (1990) The sol-gel process. Chem Rev 90:33-72

26. Brinker CJ, Hurd AJ, Schunk PR et al (1992) Review of sol-gel thin film formation. J Non-Cryst Solids 147-148:424-436. https ://doi.org/10.1016/S0022-3093(05)80653-2

27. Wright JD, Sommerdijk NAJM (2001) Sol-gel materials: chemistry and applications. Gordon and Breach Science Publishers, Amsterdam

28. Rao CNR, Biswas K (ed) (2015) Section 10.5-sol-gel synthesis. In: Essentials of inorganic materials synthesis, 1 st edn. Wiley, Hoboken, pp 81-85

29. Danks AE, Hall SR, Schnepp Z (2016) The evolution of "solgel" chemistry as a technique for materials synthesis. Mater Horiz 3:91-112. https://doi.org/10.1039/c5mh00260e

30. Klein LC (1985) Sol-gel processing of silicates. Ann Rev Mater Sci 15:227-248

31. Goldstein JI, Newbury DE, Echlin P et al (1994) Scanning electron microscopy and X-ray microanalysis, 2nd edn. Plenum Press, New York

32. Lana SLB, Seddon AB (1998) X-ray diffraction studies of sol-gel derived ORMOSILs based on combinations of tetramethoxysilane and trimethoxysilane. J Sol-Gel Sci Technol 13:461-466. https:// doi.org/10.1023/A:1008685614559

33. ICDD (2016) International Centre for Diffraction Data. Newtown Square

34. Kulkarni DK, Prakash CS (1994) Structural and magnetic properties of $\mathrm{CaAl}_{4} \mathrm{Fe}_{8} \mathrm{O}_{19}$. Bull Mater Sci 17:35-39

35. Kimmel G, Sariel J, Zabicky J, Goncharov E (2003) ICDD Grantin-Aid. Western Michigan University, Kalamazoo

36. Ponce-Castañeda S, Martínez JR, Ruiz F et al (2002) Synthesis of $\mathrm{Fe}_{2} \mathrm{O}_{3}$ species embedded in a silica xerogel matrix: a comparative study. J Sol-Gel Sci Technol 25:29-36

37. Cannas C, Casula MF, Concas G, Corrias A, Gatteschi D, Falqui A, Musinu A, Sangregorio C, Spano G (2001) Magnetic properties of $\gamma-\mathrm{Fe}_{2} \mathrm{O}_{3}-\mathrm{SiO}_{2}$ aerogel and xerogel nanocomposite materials. J Mater Chem 11:3180-3187. https://doi.org/10.1039/b1045 $62 \mathrm{~h}$

38. Klein LC (ed) (1994) Nanocomposite fabrication for transparent windows. In: Sol-gel optics: processing and applications, 1 st edn. Springer, New York

39. Trnka M, Houzar S (2002) Moldavites: a review. Bull Czech Geol Surv 77:283-302

Publisher's Note Springer Nature remains neutral with regard to jurisdictional claims in published maps and institutional affiliations. 